\title{
RMetS
}

Royal Meteorological Society

\section{Global radiative and climate effect of the water vapour continuum at visible and near-infrared wavelengths}

\author{
Gaby Rädel, ${ }^{\mathrm{a}, \mathrm{b}}$ Keith P. Shine ${ }^{\mathrm{a} \star}$ and Igor V. Ptashnik ${ }^{\mathrm{a}, \mathrm{c}}$ \\ ${ }^{a}$ Department of Meteorology, University of Reading, UK \\ ${ }^{\mathrm{b}}$ Max Planck Institute for Meteorology, Hamburg, Germany \\ ${ }^{c}$ V.E. Zuev Institute of Atmospheric Optics, Tomsk, Russia \\ ${ }^{\star}$ Correspondence to: K. P. Shine, Department of Meteorology, University of Reading, Earley Gate, PO Box 243, Reading, RG6 6BB, \\ UK. E-mail: k.p.shine@reading.ac.uk
}

\begin{abstract}
Recent laboratory measurements show that absorption by the water vapour continuum in near-infrared windows may be about an order of magnitude higher than assumed in many radiation codes. The radiative impact of the continuum at visible and near-infrared wavelengths is examined for the present day and for a possible future warmer climate (with a global-mean total column water increase of $33 \%$ ). The calculations use a continuum model frequently used in climate models ('CKD') and a continuum model where absorption is enhanced at wavelengths greater than $1 \mu \mathrm{m}$ based on recent measurements ('CAVIAR'). The continuum predominantly changes the partitioning between solar radiation absorbed by the surface and the atmosphere; changes in top-of-atmosphere net irradiances are smaller. The global-mean clear-sky atmospheric absorption is enhanced by $1.5 \mathrm{~W} \mathrm{~m}^{-2}$ (about $2 \%$ ) and $2.8 \mathrm{~W} \mathrm{~m}^{-2}$ (about 3.5\%) for CKD and CAVIAR respectively, relative to a hypothetical no-continuum case, with all-sky enhancements about $80 \%$ of these values. The continuum is, in relative terms, more important for radiation budget changes between the present day and a possible future climate. Relative to the no-continuum case, the increase in globalmean clear-sky absorption is $8 \%$ higher using CKD and almost $20 \%$ higher using CAVIAR; all-sky enhancements are about half these values. The effect of the continuum is estimated for the solar component of the water vapour feedback, the reduction in downward surface irradiance and precipitation change in a warmer world. For CKD and CAVIAR respectively, and relative to the no-continuum case, the solar component of the water vapour feedback is enhanced by about 4 and $9 \%$, the change in clear-sky downward surface irradiance is 7 and $18 \%$ more negative, and the global-mean precipitation response decreases by 1 and $4 \%$. There is a continued need for improved continuum measurements, especially at atmospheric temperatures and at wavelengths below $2 \mu \mathrm{m}$.
\end{abstract}

Key Words: radiative transfer; solar radiation; self-continuum; foreign-continuum; global dimming; water vapour feedback

Received 1 August 2013; Revised 26 March 2014; Accepted 10 April 2014; Published online in Wiley Online Library 19 June 2014

\section{Introduction}

Water vapour is the most important gaseous absorber in the Earth's atmosphere (e.g. Kiehl and Trenberth, 1997). It plays a key role in the determination of the Earth's radiative budget and, because the atmospheric abundance of water vapour is sensitive to changes in temperature, it plays an important role in climate change. This article focuses on the role that the water vapour continuum plays in the absorption of solar radiation. There are significant uncertainties in the nature and causes of the water vapour continuum at near-infrared wavelengths (e.g. Ptashnik et al., 2011b; Shine et al., 2012). Until relatively recently, there was a dearth of measurements. An extensive series of laboratory measurements of the near-infrared continuum has been reported, as part of the UK-based CAVIAR (Continuum Absorption at Visible and Infrared wavelengths and its Atmospheric Relevance) consortium, for the self-continuum (i.e. due to interactions between water vapour molecules: Ptashnik et al., 2011a) and the foreign-continuum (i.e. due to the interaction of water vapour with other molecules: Ptashnik et al., 2012). These measurements indicate that the continuum in the near-infrared windows around $1.25,1.6,2.1$ and $3.8 \mu \mathrm{m}$ is significantly 
stronger, by factors of about 10 for the self-continuum, and by up to about a factor of 100 for the foreign-continuum, in some windows and at some temperatures, than found in the widely-used CKD (Clough-Kneizys-Davies) semi-empirical continuum model and its successor MT_CKD (Mlawer-Tobin CKD) (Mlawer et al., 2012).

Ptashnik et al. (2012) used plausible representations of the temperature dependence of the continuum (see later) to calculate the impact of the new CAVIAR continuum measurements on the atmospheric absorption of solar radiation, using clear-skies and zonal and seasonal-mean atmospheres, relative to those found using MT_CKD version 2.5. The global and annual-mean atmospheric absorption increased by $0.74 \mathrm{~W} \mathrm{~m}^{-2}$ due to the selfcontinuum and by $0.46 \mathrm{~W} \mathrm{~m}^{-2}$ due to the foreign-continuum. The enhanced self-continuum absorption was particularly peaked in the Tropics. The total global-mean increase, $1.2 \mathrm{~W} \mathrm{~m}^{-2}$, is approximately $1.5 \%$ of the calculated clear-sky solar absorption.

This article extends the calculations of Ptashnik et al. (2012) to all-sky atmospheres including longitudinal as well as latitudinal variations, and considers the impact on surface and top-of-theatmosphere fluxes, as well as on atmospheric absorption. The article then explores the impact of the continuum on several aspects associated with the expected increases in atmospheric water vapour in coming decades as a result of climate change. The work can be considered in some ways as complementary to Paynter and Ramaswamy (2012). Paynter and Ramaswamy (2012) reported the impact of recent self-continuum measurements that predated those of Ptashnik et al. (2011a) on calculated clear-sky atmospheric absorption, relative to the CKD and MT_CKD models. They also explored the possible impacts of experimental uncertainties and changing water vapour amounts on atmospheric absorption, mostly for an idealized constant solar zenith angle case. Paynter and Ramaswamy (2012) note that had they used the self-continuum results of Ptashnik et al. (2011a) it would have given an impact on atmospheric absorption towards the upper end of their uncertainty range. Paynter and Ramaswamy (2012) essentially used the foreigncontinuum presented in MT_CKD version 2.5 and so did not include the enhancements to the foreign-continuum strength reported by Ptashnik et al. (2012).

While the laboratory data should represent our most robust understanding of the strength of the continuum, it is important to emphasize their limitations and also to contrast them with the assumptions underlying the CKD and MT_CKD models. One difficulty with laboratory measurements of the strength of the continuum (and particularly the self-continuum) in near-infrared windows is that reliable measurements are currently only possible for high water vapour densities that require measurements at relatively high temperatures (and hence vapour pressures). For application to the atmosphere, these measurements have to be extrapolated to lower temperatures; in the absence of a robust theory explaining the physical cause of the continuum in the windows (both water dimers and the contribution of the far wings of water vapour lines are possible explanations) there are significant uncertainties associated with doing this. The sources of error and the size of the uncertainties are discussed in detail in Ptashnik et al. (2011a, 2012) and as noted above, Paynter and Ramaswamy (2012) examine some of the effects of such uncertainties on calculations of the short-wave absorption.

While the CAVIAR continuum is largely based on laboratory measurements in the near-infrared, the CKD and MT_CKD models are derived in a quite different manner (Mlawer et al., 2012). Within the windows, the continuum is derived using an empirical adjustment of the far-wing line-shape of water vapour, so as to fit measurements of the mid-infrared (around $10 \mu \mathrm{m}$ ) continuum; this adjusted line shape is then applied to all spectral regions, including the near-infrared. However, this adjusted lineshape does not explain the observed strength of continuum absorption in the $3.8 \mu \mathrm{m}$ window and so MT_CKD_2.5 uses a scaling factor which enhances the absorption by up to about an order of magnitude, a factor that was not applied in earlier versions. It is important to note that the scaling was not applied to other near-infrared windows, although Mlawer et al. (2012) note that the need for this scaling factor indicates that their adjusted line shape is probably not appropriate in the near-infrared.

Although there is a general dearth of continuum measurements with which to compare, the CAVIAR self- and foreign- continua in the $3.8 \mu \mathrm{m}$ window measurements agree, within the uncertainties, with the laboratory measurements of Baranov (2011) and Baranov and Lafferty $(2011,2012)$, as well as with some earlier selfcontinuum measurements reported in Ptashnik et al. (2011b); the older measurements of Burch and Alt (1984) are lower than the newer laboratory measurements in the centre of the window by a factor of about 6 at near-room temperature (and are lower than the empirically adjusted MT_CKD_2.5 by around a factor of 3), but are in much better agreement at higher temperatures. In the 2.1 and $3.8 \mu \mathrm{m}$ windows, measurements involving some of the CAVIAR authors, but made using somewhat different experimental set-ups to those used in CAVIAR (all used the same type of Fourier Transform Spectrometer, but different long and short pathlength gas cells are used), support the CAVIAR results (Paynter et al., 2009; Ptashnik et al., 2013), although they are higher than the Bicknell et al. (2006) measurements in the centre of the $2.1 \mu \mathrm{m}$ window by about a factor of 4 . Nevertheless, it is certainly the case that, as shown in Ptashnik et al. (2011b, 2012), there are significant uncertainties in laboratory-derived estimates of the continuum, especially near room-temperature (when such measurements are possible), that arise from possible baseline drifts in the spectrometer measurements. The need to extrapolate these measurements to atmospheric temperatures (see section 2) adds an additional uncertainty to the use of the laboratory measurements. The CKD model (for which no uncertainty estimates are available) generally lies around the lower end of the CAVIAR uncertainty estimates and so could be regarded as the minimum likely contribution of the continuum presented here.

Recently, Ptashnik et al. (2013) have reported new measurements at near-room-temperature in the $1.6 \mu \mathrm{m}$ window region. These appear to show that at these temperatures the selfcontinuum in this window is about as strong as that in the neighbouring $2.1 \mu \mathrm{m}$ window, in contrast to the higher temperature measurements (Ptashnik et al., 2011b) that indicate it is more than an order of magnitude weaker (Figure 1). As noted by Ptashnik et al. (2013) and Mondelain et al. (2013) there is considerable disagreement between near-room-temperature laboratory measurements using different techniques in this window, for reasons that are not currently clear. We thus exclude these more recent $1.6 \mu \mathrm{m}$ room-temperature window measurements here and use instead the (extrapolated) measurements reported by Ptashnik et al. (2011a).

It must be stressed that the Mondelain et al. (2013) measurements do not contradict the CAVIAR measurements (Ptashnik et al., 2011b) used here, as they are made at different temperatures. At the long-wavelength edge of the $1.6 \mu \mathrm{m}$ window, the CAVIAR $374 \mathrm{~K}$ measurements are, after applying the temperature dependence described in section 2, quite consistent with the $296 \mathrm{~K}$ measurements of Mondelain et al.; in the centre of the window, a weaker temperature dependence than we use here would be required to agree with the best estimate of Mondelain et al., although the continuum strengths remain consistent within the stated uncertainties of the two sets of measurements. The CAVIAR measurements are more consistent with the $298 \mathrm{~K}$ measurements of Bicknell et al. (2006) at $1.6 \mu \mathrm{m}$, which are about a factor of three stronger than those of Mondelain et al. (2013); Bicknell et al.'s $298 \mathrm{~K}$ measurements are about an order of magnitude stronger than the CAVIAR $374 \mathrm{~K}$ measurement, which is consistent with the temperature dependence given in Eq. (1) and Figure 1, which would yield an increase of about a factor of 8 between the 374 and $298 \mathrm{~K}$, for this wavelength. 

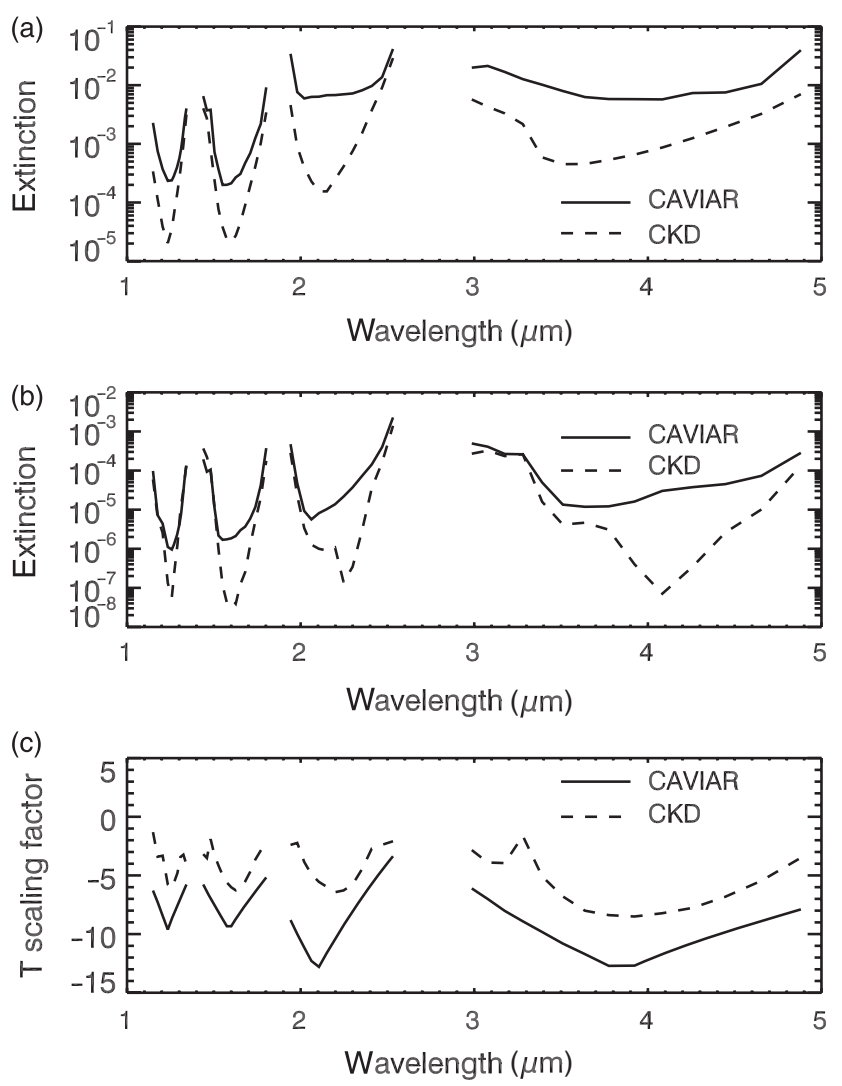

Figure 1. Extinction coefficient as a function of wavelength for two different descriptions (CAVIAR and CKD) of the water vapour (a) self-continuum and (b) foreign-continuum at $273 \mathrm{~K}$, and (c) the temperature-scaling coefficient of the self-continuum as implemented in the Edwards-Slingo radiation code. The units of extinction in (a) and (b) are $\mathrm{m}^{5} \mathrm{~kg}^{-1} \mathrm{~mol}^{-1}$ (see text).

Ptashnik et al. (2012) showed that the impact of the enhanced self- and foreign- continua on atmospheric absorption using the CAVIAR continuum is predominantly in the two longer wavelength $(2.1$ and $3.8 \mu \mathrm{m})$ windows, and by the $2.1 \mu \mathrm{m}$ window in particular, as the measured continuum is strongest in these windows. The effect of continuum strength (and the absolute change in continuum strength between CAVIAR and MT-CKD) dominates over the fact that there is more solar radiation available to be absorbed in the shorter wavelength windows. Hence the higher uncertainties in the $1.6 \mu \mathrm{m}$ window in the CAVIAR continuum measurements are of less importance from the point of view of the atmospheric energy budget Clearly, however, if the more recent measurements of Ptashnik et al. (2013) in that window prove to be robust, it would require a significant strengthening of the assumed temperature dependence adopted in this article, and the extra absorption in the $1.6 \mu \mathrm{m}$ window would become much more important than reported here; more experimental support is required before these more recent measurements can be used for this purpose.

In section 2 the radiative transfer model used here, and its modification to include the CAVIAR continuum, will be described, and the different inputs to the model will be explained. Section 3 will describe results for the present-day atmosphere and section 4 will examine the impact of the new continuum in a warmer and moister future climate.

\section{Methodology}

To estimate the global change in solar irradiance due to the different descriptions of the water vapour continuum, we use the off-line version of the Edwards and Slingo (ES) (1996) radiation scheme, used in the UK Met Office Unified Model. The code is based on the two-stream equations and employs the $\delta$-Eddington approximation at solar wavelengths. The spectral resolution in the ES code can be varied. We use a standard spectral file prepared at the UK Met Office, with 220 spectral bands, of which 150 bands lie at wavelengths less than $1 \mu \mathrm{m}$ and 70 bands lie within the nearinfrared region of $1-5 \mu \mathrm{m}$. This differs from the normal climate model resolution of ES which has eight spectral bands. This enables us to incorporate a more detailed representation of the new continuum; in addition, in versions of ES with lower spectral resolution, the spectral line absorption and foreign-continuum are combined, which makes it more difficult to modify the foreign-continuum strength.

The default water vapour continuum in ES is version 2.1 of CKD (Mlawer et al., 2012). There were no significant developments in the near-infrared water vapour continuum between CKD_2.1 and its final version CKD_2.4.1 (which is widely used in climate models), although there had been significant changes in the versions prior to CKD_2.1 (e.g. Zhong et al., 2002; Ptashnik and Shine, 2003). Changes between CKD_2.4.1 and early versions of MT_CKD mostly affected the foreign-continuum strength leading to a decrease in the wavenumber-averaged calculated solar absorption (e.g. Paynter and Ramaswamy, 2011, 2012). In MT_CKD_2.5, self-continuum coefficients in the $3.8 \mu \mathrm{m}$ $\left(2050-3150 \mathrm{~cm}^{-1}\right)$ window region were increased by a scaling factor, of up to a factor of 10 in the centre of this window (see section 1). This increased the calculated short-wave absorption, but not to the levels found in CKD_2.4.1; for global-mean clear skies, the self- and foreign- continua are about equally important in MT_CKD_2.5, whereas in CKD_2.4.1, the foreigncontinuum dominated (Paynter and Ramaswamy, 2012). It is emphasized that the results presented here as 'CKD' are CKD as implemented within the ES code, as incorporation of the continuum within radiative transfer codes necessarily requires some level of approximation.

Gaseous absorption is modelled using the exponential sum fitting technique applied to line-by-line transmittances using the HITRAN-92 database There have been numerous revisions to near-infrared water vapour line parameters catalogued in the HITRAN database since this version. The most recent release is HITRAN2012 (Rothman et al., 2013). These revisions impact on calculations of near-infrared absorption (e.g. Zhong et al., 2001; Ptashnik and Shine, 2003; Tallis et al., 2011; Kim and Ramanathan, 2012) - the effect of these changes on the absorption by water vapour will be noted where appropriate.

Within ES, the self- and foreign- continua are treated separately, with three coefficients per spectral band each, representing extinction, temperature scaling and pressure scaling. The CAVIAR continuum was implemented in ES by replacing the extinction and temperature-scaling coefficients for the self-continuum, and the extinction coefficient for the foreign-continuum in the nearinfrared window regions (Table 1). The in-band continuum is much less important for atmospheric absorption, as absorption is generally dominated by water vapour lines (e.g. Ptashnik et al., 2004), although the in-band foreign-continuum can make a contribution to the total short-wave absorption in the weaker shorter wavelength bands of water vapour (Paynter and Ramaswamy, 2012). In any case the differences between CKD and recent measurements are much smaller (e.g. Paynter and Ramaswamy, 2012) in the bands than is found in the windows. Hence this work focuses on the effect of differences between CKD and CAVIAR in several near-infrared windows.

As CAVIAR laboratory observations are currently only available for wavelengths greater than $1 \mu \mathrm{m}$ for the selfcontinuum, and $1.15 \mu \mathrm{m}$ for the foreign-continuum, the original CKD continuum is retained for wavelengths lower than $1 \mu \mathrm{m}$. It should be noted, as shown by Paynter and Ramaswamy (2011), that in general the CKD continuum is somewhat stronger than MT_CKD at these lower wavelengths; however, the contribution of this difference to the radiation budget will be small (see Fig. 7 of Paynter and Ramaswamy (2011)).

The self-continuum has a strong temperature dependence. As the measurements of Ptashnik et al. (2011a) were mostly 
Table 1. Parameters in Eq. (1) for the wavenumber ranges corresponding to the different window regions.

\begin{tabular}{lcccc}
\hline Window $(\mu \mathrm{m})$ & Wavenumber range & $D_{\mathrm{o}}$ & $v_{\mathrm{o}}$ & $\Delta v$ \\
\hline 3.8 & $2000-3000$ & 4500 & 2600 & 1500 \\
2.1 & $3900-5200$ & 4500 & 4780 & 1200 \\
1.6 & $5500-7100$ & 3100 & 6300 & 1800 \\
1.25 & $7400-8600$ & 3100 & 8100 & 1800 \\
1.1 & $9000-9550$ & 3100 & 9600 & 1800 \\
\hline
\end{tabular}

Except for the first column, all numbers have units of $\mathrm{cm}^{-1}$.

made at elevated temperatures (293-472 K), an extrapolation to atmospheric conditions is necessary. We use a modified form of the method of Ptashnik et al. (2011a) and assume that the temperature dependence follows a wavenumber-dependent exponential form. The absorption cross-sections $C_{\mathrm{s}}\left(v, T_{\mathrm{m}}\right)$ (in $\mathrm{cm}^{2}$ molecule $\mathrm{atm}^{-1}$ ), measured at $T_{\mathrm{m}}=293 \mathrm{~K}$ were extrapolated down to the reference temperature $T_{\mathrm{o}}=273 \mathrm{~K}$ using the formula:

$C_{s}\left(v, T_{\mathrm{o}}\right)=C_{\mathcal{s}}\left(v, T_{\mathrm{m}}\right) \exp \left\{D_{\mathrm{o}, i}\left(\frac{1}{T_{\mathrm{o}}}-\frac{1}{T_{\mathrm{m}}}\right)\left(1-\left|\frac{v-v_{\mathrm{o}, i}}{\Delta v_{i}}\right|\right)\right\}$

where $i$ is the index over the different window regions. The values for $D_{0}, v_{0}$ and $\Delta v_{0}$ are given in Table 1 . They were derived from best-fits of the values of $C_{\mathrm{s}}\left(\nu, T_{\mathrm{m}}\right)$ for $T_{\mathrm{m}}=374$, 402,433 and $470 \mathrm{~K}$ for the $1.1,1.35$ and $1.6 \mu \mathrm{m}$ windows and $T_{\mathrm{m}}=293,350,374$ and $402 \mathrm{~K}$ for the 2.1 and $3.8 \mu \mathrm{m}$ windows (Ptashnik et al., 2011a). The temperature dependence (Eq. (1)) (apart from the third factor in the exponent) is similar to the simplified form which can be expected for water dimer absorption coefficient in the near-infrared at close to atmospheric conditions (Eq. (1) in Ptashnik et al., 2011a). The third factor in the exponent accounts for wavenumber variation of the temperature dependence which is weaker at the edges compared to the centres of the windows (Ptashnik et al., 2011a). ES assume that the selfcontinuum strength has the functional form $\left(T / T_{\mathrm{o}}\right)^{\mathrm{b}}$ where $b$ is a wavenumber-dependent parameter. Equation (1) is used to derive the value of $b$.

The cross-section for the foreign-continuum was taken to be the average of the values obtained in Ptashnik et al. (2012) for temperatures $350-400 \mathrm{~K}$. Within the accuracy of the CAVIAR measurements, there is no clear temperature dependence of the foreign-continuum; thus, in common with $\mathrm{CKD}$, we assume the foreign-continuum to be a constant with temperature.

In the ES code, the adopted units for the continuum strength are $\mathrm{m}^{5} \mathrm{~kg}^{-1} \mathrm{~mol}^{-1}$, which can be interpreted as the cross-section per unit mass of water vapour $\left(\mathrm{m}^{2} \mathrm{~kg}^{-1}\right)$ per molar density $\left(\mathrm{mol} \mathrm{m}{ }^{-3}\right.$ ) (of water vapour in the case of the self-continuum and dry air in the case of the foreign-continuum). At a given temperature $T(\mathrm{~K})$ the conversion factor between the continuum absorption cross-section units in Eq. (1) and the absorption coefficient used in ES is given by:

$$
\begin{aligned}
C & {\left[\mathrm{~m}^{5} \mathrm{~kg}^{-1} \mathrm{~mol}^{-1}\right] } \\
& =7.49 \times 10^{19}\left(T / T_{\mathrm{o}}\right) C\left[\mathrm{~cm}^{2} \text { molecule }{ }^{-1} \mathrm{~atm}^{-1}\right] .
\end{aligned}
$$

The extinction coefficients for the CKD and CAVIAR selfand foreign- continua in ES units and the temperature scaling coefficient $b$ for the self-continuum are shown in Figure 1.

The atmospheric calculations are performed on a $3.75^{\circ} \times$ $2.5^{\circ}$ grid with 19 vertical levels stretching from the surface to the stratopause. Solar insolation is calculated as a function of latitude and day of the year (one calculation per month). The diurnal variation in solar zenith angle was represented using a sixpoint Gaussian integration during the daytime, for mid-month conditions. Temperature profiles are derived from the European
Centre for Medium-Range Weather Forecasts ERA-40 re-analysis (Uppala et al., 2005) and ozone profiles are from Li and Shine (1995). Cloud amount and surface visible albedos are from the International Satellite Cloud Climatology Project (Rossow and Schiffer, 1999), which provides information on the average cloud cover, optical depth and cloud-top pressure. The surface albedos are presumed constant with wavelength which is a simplification. This will have most impact over snow and ice surfaces, where the near-infrared albedo will be overestimated leading to some increase in the amount of surface-reflected radiation that can be absorbed. Over vegetated surfaces, the impact on the effect of the continuum will be limited, as in the window regions in which the continuum absorption is greatest $(2.1$ and $3.8 \mu \mathrm{m})$, the surface albedo is close to the visible values. Aerosols are not included.

To investigate the impact of future climate change on the continuum absorption, present-day and future atmospheric water vapour profiles were taken from calculations using the Met Office Unified Model (HADGEM1) runs as archived in the Coupled Model Intercomparison Project phase 3 (CMIP3) multi-model database. For the present day, results from the 'climate of the twentieth century' experiment are extrapolated onto our model grid using averages of the last ten years (1990-1999) of the integration. The global-annual-mean precipitable water was $22.3 \mathrm{~kg} \mathrm{~m}^{-2}$, which is somewhat lower than some recent climatologies (e.g. Sudradjat et al. (2005) indicate values of $23.9-25.1 \mathrm{~kg} \mathrm{~m}^{-2}$, while the multi-year annual-mean in Vonder Haar et al. (2012) is $25.3 \mathrm{~kg} \mathrm{~m}^{-2}$ ) which will slightly affect the total absorption computed here, as noted later. We note that the distribution of water vapour amount, as well as the globalmean, is important in determining the global-mean short-wave absorption.

For the calculations of the continuum impact in a future, warmer atmosphere, water vapour profiles from another HADGEM1 CMIP3 experiment were taken in which an instantaneous doubling of $\mathrm{CO}_{2}$ was imposed in 2006. Ten-year means (2067-2076) of water vapour mixing ratios were used. For this ten-year mean, the increase in global-mean total atmospheric column water vapour was $33 \%$ and the global-mean surface temperature increase was $4.4 \mathrm{~K}$.

Results are reported for three cases. In the 'no continuum case' the water vapour continuum is neglected completely at all wavelengths. In the 'CKD' case, the CKD water vapour continuum is included at all wavelengths. In the 'CAVIAR' case, the CKD continuum values in the windows at wavelengths greater than $1 \mu \mathrm{m}$ are replaced by CAVIAR values in the near-infrared windows (Table 1), with CKD retained at other wavelengths.

\section{Impact of the continuum on the calculations of the present- day solar radiation budget}

Table 2 shows the global annual-mean impact of the water vapour continuum on the net (downward) irradiances at the top of the atmosphere (TOA) and the surface, and for the atmospheric absorption, for both clear- and all- skies. Absolute values are shown for the no-continuum case, together with the change in these values on including the CKD and the CAVIAR continua. Results are shown for wavelengths less than $1 \mu \mathrm{m}$, wavelengths greater than $1 \mu \mathrm{m}$, and for the total change.

The global-mean short-wave radiation budget is in reasonable agreement with other analyses, with an all-sky TOA net irradiance (often referred to as the absorbed solar radiation) of about $241 \mathrm{~W} \mathrm{~m}^{-2}$, an atmospheric absorption of about $67-69 \mathrm{~W}$ $\mathrm{m}^{-2}$ and a net surface irradiance of about $175 \mathrm{~W} \mathrm{~m}^{-2}$. Other recent estimates have a range of values for the global-mean atmospheric absorption (with a consequent effect on the net surface irradiance, as the TOA net irradiance is well-constrained from observations). Trenberth and Fasullo (2012) give $78 \mathrm{~W}$ $\mathrm{m}^{-2}$, Wild et al. (2013) give $79 \mathrm{~W} \mathrm{~m}^{-2}$ (with a 2-sigma uncertainty range of $74-91 \mathrm{~W} \mathrm{~m}^{-2}$ ), Stephens et al. (2012) 
Table 2. Global- and annual-mean net downward solar irradiance at the top of atmosphere (TOA) and the surface, and the net atmospheric absorption for clear and all skies calculated for the present-day atmosphere.

\begin{tabular}{|c|c|c|c|c|c|c|c|c|c|c|}
\hline \multirow[b]{2}{*}{ Case } & \multirow[b]{2}{*}{ Component } & \multicolumn{3}{|c|}{ No continuum } & \multicolumn{3}{|c|}{ CKD cont } & \multicolumn{3}{|c|}{ CAVIAR cont } \\
\hline & & vis & nir & total & vis & nir & total & vis & nir & total \\
\hline \multirow[t]{3}{*}{ Clear skies } & TOA & 198.6 & 95.5 & 294.1 & 0.03 & 0.16 & 0.19 & 0.03 & 0.33 & 0.36 \\
\hline & Surface & 174.5 & 56.3 & 230.8 & -0.21 & -1.13 & -1.34 & -0.21 & -2.21 & -2.42 \\
\hline & Atmosphere & 24.1 & 39.3 & 63.4 & 0.24 & 1.29 & 1.53 & 0.24 & 2.54 & 2.78 \\
\hline \multirow[t]{3}{*}{ All skies } & TOA & 159.0 & 82.3 & 241.4 & 0.07 & 0.24 & 0.31 & 0.07 & 0.40 & 0.47 \\
\hline & Surface & 135.0 & 39.6 & 174.6 & -0.23 & -0.77 & -1.00 & -0.23 & -1.47 & -1.70 \\
\hline & Atmosphere & 24.1 & 42.7 & 66.8 & 0.30 & 1.01 & 1.31 & 0.30 & 1.87 & 2.17 \\
\hline
\end{tabular}

The 'no continuum' values are given as absolute values, and the 'CKD continuum' and 'CAVIAR continuum' values are given as differences from the 'no continuum' values. For each parameter and continuum, the first value ('vis') is the wavelength-integrated values for all wavelengths less than $1 \mu \mathrm{m}$, the second value ('nir') is for wavelengths from 1 to $5 \mu \mathrm{m}$ and the final value is the sum of these. The total may not agree with the sum of the components because of rounding. All values are in $\mathrm{W} \mathrm{m} \mathrm{m}^{-2}$.

give $75 \pm 10 \mathrm{~W} \mathrm{~m}^{-2}$ and Kim and Ramanathan (2012) give $82 \pm$ $8 \mathrm{~W} \mathrm{~m}^{-2}$. We expect our value to be biased somewhat low (e.g. Kim and Ramanathan (2012) calculate an effect of $4 \mathrm{~W} \mathrm{~m}^{-2}$ due to aerosol absorption, $2 \mathrm{~W} \mathrm{~m}^{-2}$ from three-dimensional cloud effects, and the improved water vapour line strength database could enhance absorption by a further few $\mathrm{W} \mathrm{m} \mathrm{m}^{-2}$ relative to the HITRAN-92 spectral database used here). The relatively low precipitable water used here is also likely to cause an underestimate of absorption by about $1 \mathrm{~W} \mathrm{~m}^{-2}$ by simple scaling with the results presented in section 4 . Nevertheless the global-mean atmospheric absorption is within the range quoted by Stephens et al. (2012). The calculated short-wave cloud radiative effect at the top of the atmosphere is $-53 \mathrm{~W} \mathrm{~m}^{-2}$, in reasonable agreement with the value of about $-47 \mathrm{~W} \mathrm{~m}^{-2}$ (Kato et al., 2013) diagnosed from satellite observations. Kato et al. (2013) also derive a surface short-wave cloud radiative effect of $-50 \mathrm{~W} \mathrm{~m}^{-2}$, in reasonable agreement with the value of $-55 \mathrm{~W} \mathrm{~m}^{-2}$ derived here.

The clear-sky results are shown in the upper rows of Table 2 . The CKD continuum increases the TOA net irradiance by $0.2 \mathrm{~W} \mathrm{~m}^{-2}$ and this increases further to $0.4 \mathrm{~W} \mathrm{~m}^{-2}$ using the CAVIAR continuum. The impact of the continuum is much more marked on the partitioning of the absorption between the atmosphere and the surface than it is on the TOA net irradiance - such a response was also found by Collins et al. (2006a) in a study where the short-wave absorption due to water vapour was increased in their radiation code. The net surface irradiance is decreased by $1.3 \mathrm{~W} \mathrm{~m}^{-2}$ using CKD, and is decreased by $2.4 \mathrm{~W} \mathrm{~m}^{-2}$ using CAVIAR. The atmospheric absorption is changed by $1.5 \mathrm{~W} \mathrm{~m}^{-2}$ using CKD, which almost doubles to $2.8 \mathrm{~W} \mathrm{~m}^{-2}$ using CAVIAR In terms of percentage impact on components of the radiation budget, the impact on atmospheric absorption is the largest. Given that our 'baseline' estimate of the atmospheric absorption is probably on the low side (see above), these changes probably constitute percentage increases of about 2 and $3.5 \%$ for CKD and CAVIAR respectively. The difference $\left(1.3 \mathrm{~W} \mathrm{~m}^{-2}\right)$ between CKD and CAVIAR is almost the same as the value $\left(1.2 \mathrm{~W} \mathrm{~m}^{-2}\right)$ found by Ptashnik et al. (2012) using a line-by-line radiation code applied to zonal-mean atmospheres.

Table 2 also shows how the inclusion of clouds affects the role of the continuum. In absolute terms, the TOA effect is increased by $25-50 \%$ relative to the clear-sky case, but the effect on the atmospheric absorption and surface irradiances is reduced by about $65-70 \%$ of the clear-sky value.

Figure 2 shows the annual- and zonal-mean changes in the TOA and surface net fluxes, and the atmospheric absorption for clear skies, using CKD and CAVIAR relative to the no-continuum case. The TOA net irradiance change shows only a modest latitudinal dependence (with a slight increase with latitude, most marked in the Northern Hemisphere), unlike the atmospheric absorption and surface irradiance which are strongly peaked in the Tropics. For CAVIAR, the atmospheric absorption is increased by more than $4 \mathrm{~W} \mathrm{~m}^{-2}$ (compared with about $2 \mathrm{~W} \mathrm{~m}^{-2}$ using CKD) in the Tropics, with the surface deprived of a similar amount of irradiance. At low latitudes, where the water vapour column is high and surface albedo relatively low, the role of the continuum is mostly to repartition absorbed solar radiation between surface absorption and atmospheric absorption, rather than to change the amount of radiation absorbed by the Earth-atmosphere system as a whole; some of the radiation that would otherwise have been absorbed by the surface is now absorbed in the atmosphere, but the effect on the TOA net irradiance is relatively small. Hence the TOA net irradiance changes are an order of magnitude smaller than the surface and atmospheric changes.

At high latitudes, the TOA net irradiance changes are of a more similar size to the other components; although there is some repartitioning of the absorbed energy between the surface and atmosphere, at high latitudes surface reflectance contributes more to the planetary albedo as there is less atmospheric absorption due to the lower water vapour columns. Hence some of the radiation that would otherwise have been reflected to space is now absorbed by the continuum and the relative impact of the continuum on the TOA net irradiance is much more important than at lower latitudes. As shown by Ptashnik et al. (2012) it is the foreign-continuum that is most effective at higher latitudes. The latitudinal variation in the increased atmospheric absorption by the continuum using CAVIAR is broadly similar to that found by Paynter and Ramaswamy (2012, their Fig. 8) when they use their updated continuum.

Figure 3 is the same as Figure 2, but for all skies. The general form of the surface and atmospheric terms is as for clear skies but about 30\% smaller. By contrast, the latitudinal variation of the TOA change, while remaining relatively flat, shows less of a high-latitude enhancement than for clear skies. With the higher TOA albedos in the all-sky case, radiation that would otherwise be reflected to space in the no-continuum case is now absorbed by the atmosphere when the continuum is present, and there is a less close compensation between the increase in atmospheric absorption and the decrease in surface irradiance.

The relative impact of the two continua varies between clear and cloudy skies, and between locations, in a quite complex way. For the no-continuum case, the global-mean atmospheric absorption increases by $3.4 \mathrm{~W} \mathrm{~m}^{-2}$ in going from clear to cloudy skies; with CKD included, this value is slightly smaller $\left(3.2 \mathrm{~W} \mathrm{~m}^{-2}\right)$ but it is more substantially affected when using CAVIAR $\left(2.8 \mathrm{Wm}^{-2}\right)$. (It is well-established in the literature (e.g. Kiehl and Trenberth, 1997; Kato et al., 2013) that the cloudy-sky absorption exceed the clear-sky absorption, because the extra absorption by liquid and ice within clouds overwhelms the fact that there is less solar radiation available to be absorbed.) Examination of Figures 2 and 3 shows that in the Tropics the effect of using CKD on atmospheric absorption is almost unchanged between clear and cloudy skies, but the CAVIAR impact remains about the same as for the globalmean. The stronger CAVIAR continuum is less effective in cloudy skies, because there is significantly less solar radiation available to be absorbed by it; the difference with CKD is particularly marked in the Tropics, where the effect of the CAVIAR self-continuum 


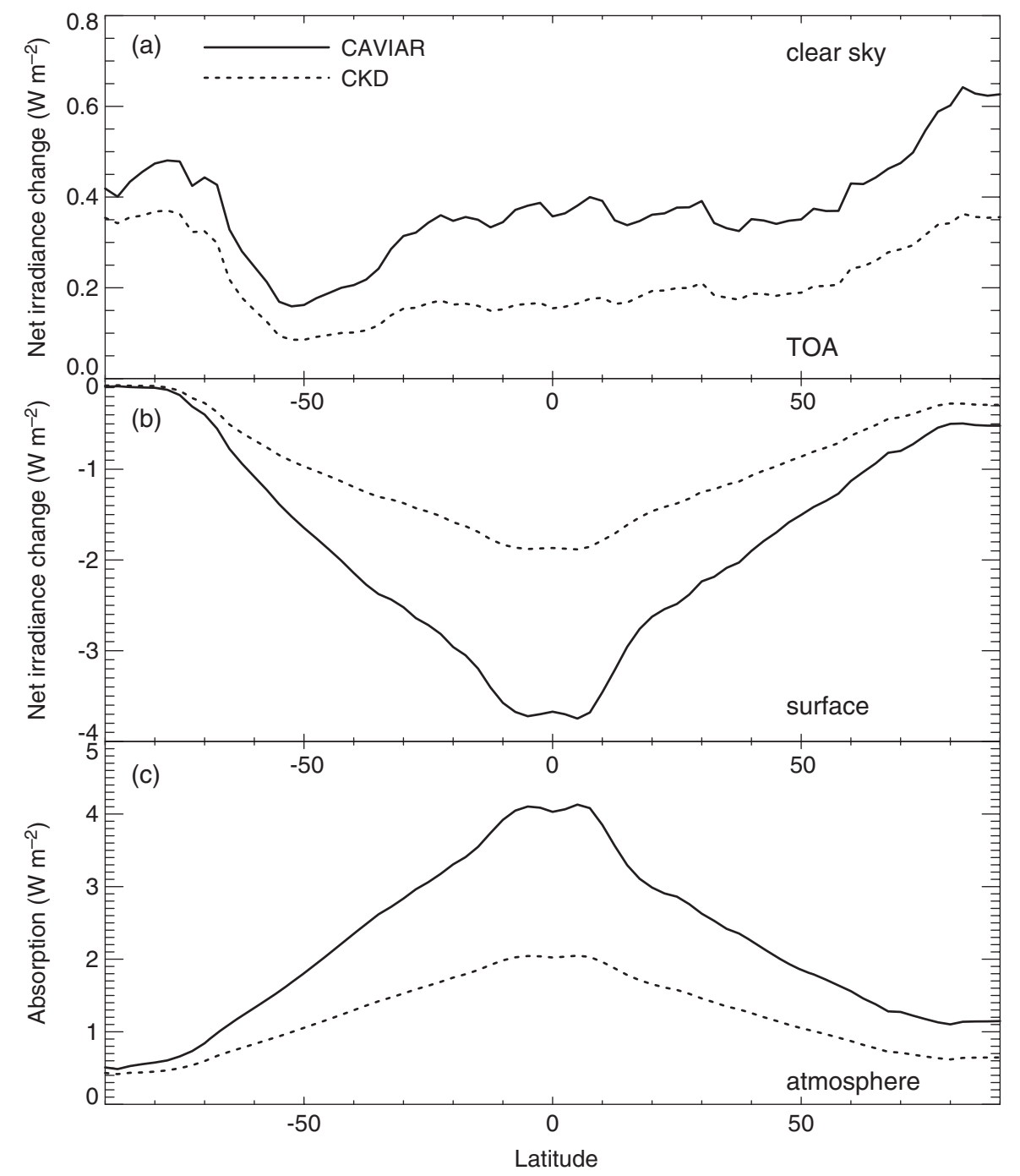

Figure 2. Annual and zonal-mean change in the net solar irradiance at (a) the top of atmosphere (TOA) and (b) the surface, and (c) the atmospheric absorption for clear skies, for the CKD continuum (dotted) and the CAVIAR continuum (solid lines), relative to the no-continuum case, in $\mathrm{W} \mathrm{m}{ }^{-2}$.

in the tropical lower troposphere is the strongest in clear skies. Considering the net surface irradiance, for the no-continuum case, clouds cause a reduction of $56 \mathrm{~W} \mathrm{~m} \mathrm{~m}^{-2}$. This cloud effect is reduced by $0.34 \mathrm{~W} \mathrm{~m}^{-2}$ using $\mathrm{CKD}$, and by $0.72 \mathrm{~W} \mathrm{~m}^{-2}$ using CAVIAR; as expected the effect of clouds is more muted when using the CAVIAR continuum, because the clear-sky opacity is higher.

\section{Possible climate change implications}

In this section, the impact of the water vapour continuum on three aspects of climate change which are affected by absorption of solar radiation are examined. The first is the water vapour feedback. This results from the fact that the atmospheric water content is sensitive to temperature so that, for example, in response to a warming of climate, the water vapour content increases. Since water vapour is a greenhouse gas, this further enhances the warming, causing a positive feedback (e.g. Colman 2001, 2003); although this effect is mostly due to the role of water vapour in the thermal infrared, there is a modest increase in short-wave absorption by water vapour which also contributes to the feedback. The second is the impact of increased water vapour amounts on the changes in downward short-wave irradiance at the surface, often referred to as 'global dimming'. The third is the role that changes in short-wave absorption may have on the global-mean precipitation response to global warming. In all cases, these terms are estimated via off-line calculations using changes in water vapour and temperature derived from climate model simulations (described in section 2) rather than direct climate model simulations. This experimental design enables the use of a radiation code with higher spectral resolution than would be possible in a climate model simulation. The inferences made here are on the basis of instantaneous changes in fluxes, when using different continua; this methodology cannot account for any further feedbacks in the climate system resulting from these flux changes.

Changes in other climate parameters (temperatures, clouds, surface albedo) on the short-wave absorption in the warmer climate are ignored here, as they are regarded as either too uncertain or second-order effects; Paynter and Ramaswamy (2012) have examined the interplay between temperature and water vapour changes. The strength of the self-continuum absorption will increase as water vapour increases (as the optical depth is proportional to the square of the vapour pressure); this is offset to some extent by the negative temperature dependence of the self-continuum cross-section (Eq. (1)). As the foreigncontinuum is assumed to be independent of temperature, this component is unaffected. Using global-mean values $(4.4 \mathrm{~K}$ warming and $33 \%$ increase in water vapour), the water vapour increase will enhance the self-continuum by $75 \%$, but even the most extreme temperature dependence in Figure 1 will cause a decrease in self-continuum strength of no more than $20 \%$ and at some wavelengths only. There will clearly be regional variations in these numbers, but the overall offset, taking into account the contribution of the foreign-continuum, is likely to be much less than $10 \%$. The results in Paynter and Ramaswamy (2012) indicate that for the short-wave atmospheric absorption, generally the offset is of the order of a few per cent, except 


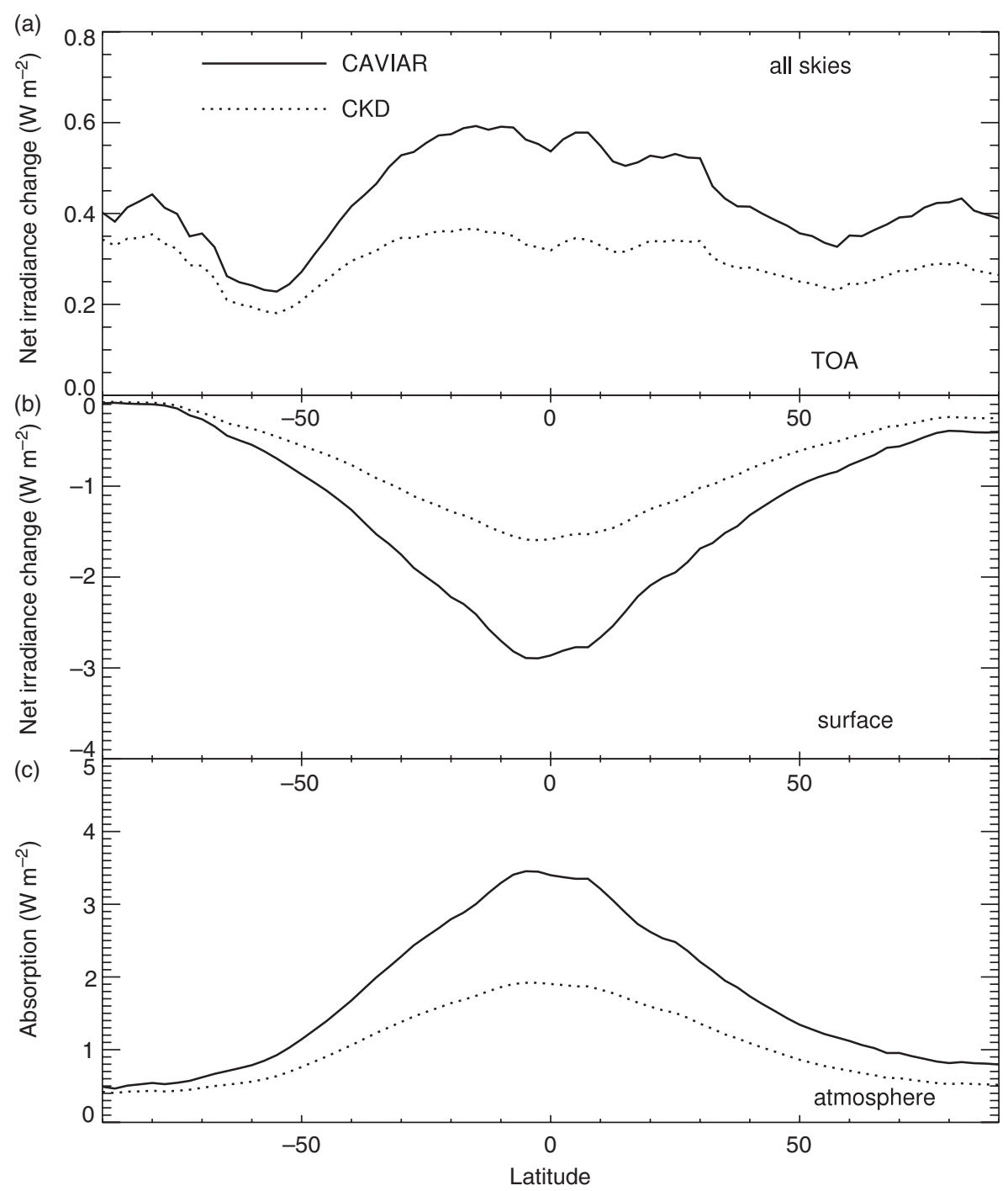

Figure 3. As Figure 2, but for the all-skies case.

in the warmest and most moist locations, where it can reach about $20 \%$.

To provide a partial evaluation of the ability of the ES code to represent the effect of changes in water vapour in the shortwave, we use results from the radiation code intercomparison of Collins et al. (2006b) in which the effect of a 20\% change to a clear-sky standard midlatitude summer atmosphere was computed, for a solar zenith angle of $53^{\circ}$. For the surface net irradiance change, Collins et al. (2006b) found line-by-line codes gave a mean value of $-5.87 \mathrm{~W} \mathrm{~m}^{-2}$ with a standard deviation of $0.31 \mathrm{~W} \mathrm{~m}^{-2}$; climate model codes gave a mean $-4.89 \mathrm{~W}$ $\mathrm{m}^{-2}$ with a much larger standard deviation of $0.98 \mathrm{~W} \mathrm{~m}^{-2}$. The 220-band version of the ES code used here gave a value of $-5.38 \mathrm{~W} \mathrm{~m}^{-2}$ without the continuum and $-5.68 \mathrm{~W} \mathrm{~m}^{-2}$ using $\mathrm{CKD}$, in good agreement with the line-by-line codes. To show the progression of values with different versions of the continuum, the line-by-line code of Mitsel' et al. (1995), as used in Ptashnik et al. (2012), found values of $-5.64 \mathrm{~W} \mathrm{~m}^{-2}$ without the continuum, $-5.95 \mathrm{~W} \mathrm{~m}^{-2}$ with CKD_2.4 (the continuum probably most widely used in the Collins et al. (2006b) line-byline calculations), $-6.07 \mathrm{~W} \mathrm{~m}^{-2}$ with MT_CKD_2.5 and $-6.63 \mathrm{~W}$ $\mathrm{m}^{-2}$ with the CAVIAR continuum. These line-by-line results are in generally good agreement with Collins et al. (2006b) and also nicely illustrate the impact of more recent versions of the continuum on the reduction in downward short-wave irradiance when water vapour is increased by $20 \%$; compared to the nocontinuum case, the effect increases from 6\% with CKD_2.4, to $7.5 \%$ with MT_CKD_2.5 and to $17.5 \%$ with the CAVIAR continuum.
Table 3. Changes in global and annual-mean net solar irradiance at the top of atmosphere (TOA) and the surface, and in the net atmospheric absorption for clear and all skies, relative to the present day, using the water vapour change (33\% increase in global-mean total water column) from a climate model integration about 65 years after the instantaneous doubling of $\mathrm{CO}_{2}$ (see section 2 for details).

\begin{tabular}{llccr}
\hline Case & Component & $\begin{array}{c}\text { No } \\
\text { continuum }\end{array}$ & $\begin{array}{c}\text { CKD } \\
\text { continuum }\end{array}$ & $\begin{array}{r}\text { CAVIAR } \\
\text { continuum }\end{array}$ \\
\hline Clear skies & TOA & 0.56 & 0.60 & 0.66 \\
& Surface net & -3.21 & -3.46 & -3.83 \\
& Surface down & -3.70 & -3.95 & -4.36 \\
\multirow{4}{*}{ All skies } & Atmosphere & 3.77 & 4.06 & 4.49 \\
& TOA & 1.06 & 1.10 & 1.16 \\
& Surface net & -2.35 & -2.47 & -2.72 \\
& Surface down & -2.73 & -2.81 & -3.11 \\
& Atmosphere & 3.46 & 3.57 & 3.88 \\
\hline
\end{tabular}

All values are in $\mathrm{W} \mathrm{m}^{-2}$

Table 3 shows the impact of the 33\% increase in atmospheric water column on short-wave absorption, for clear and all skies, and Figures 4 and 5 show the annual- and zonal-mean changes for clear and all skies. Figure 4 also shows the latitudinal dependence of the change in water vapour column as a result of the warming, to emphasize that the change is strongly peaked in the Tropics. Table 3 includes both the change in the net and downward surface irradiance, as the latter is required for 'global dimming' considerations. It is immediately apparent that the continuum plays a much larger relative role in the radiative effect of perturbations in water vapour amount than it does in the 


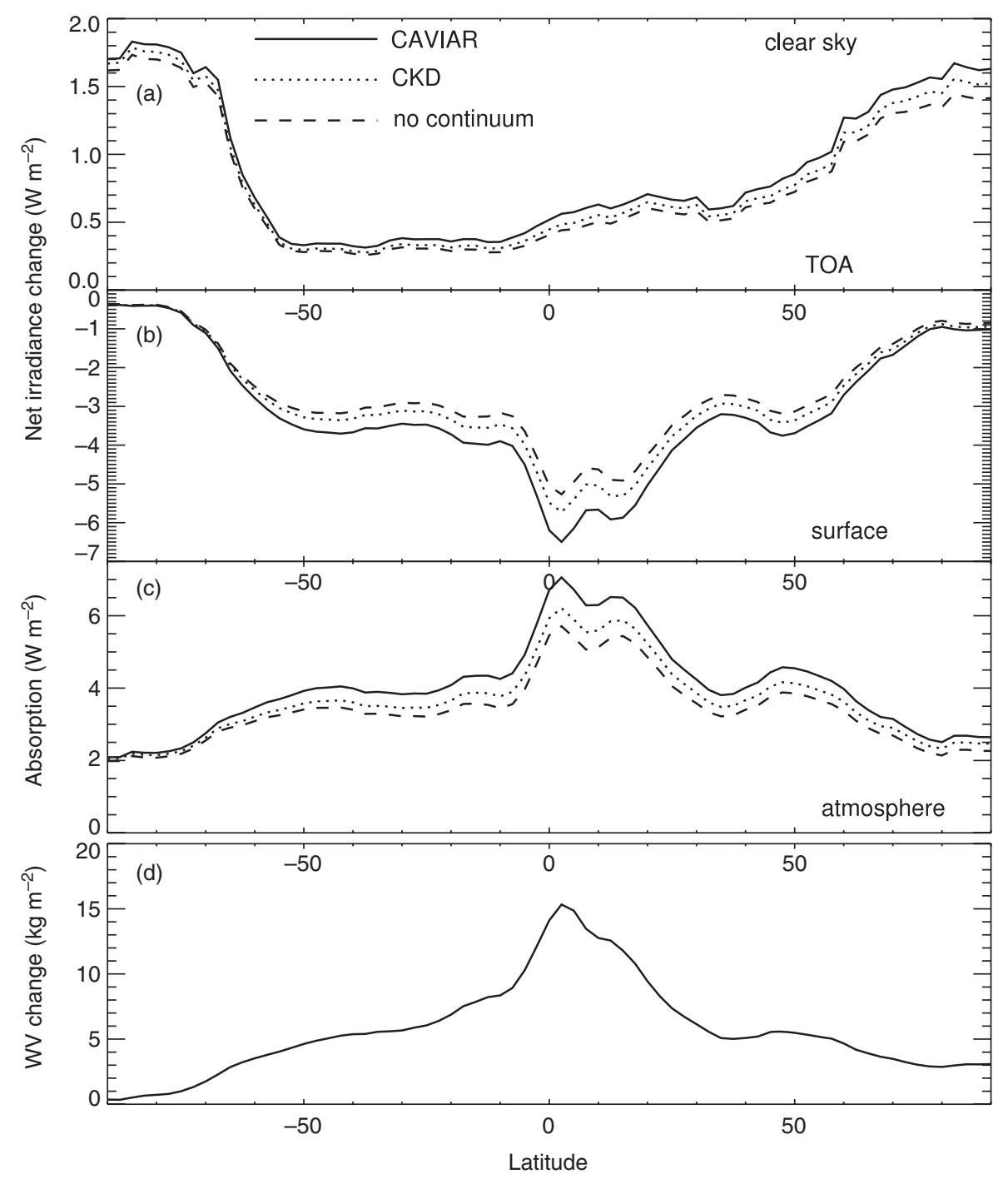

Figure 4. Impact of a global-mean increase of $33 \%$ in total water vapour column on the annual and zonal mean on the net solar irradiance at (a) the top of atmosphere (TOA) and (b) the surface, and (c) the atmospheric absorption for clear skies for the no-continuum case (dashed line), the CKD continuum (dotted) and the CAVIAR continuum (solid lines), in $\mathrm{W} \mathrm{m}^{-2}$. (d) Shows the annual and zonal-mean change in total water vapour column in $\mathrm{kg} \mathrm{m}^{-2}$.

absolute impact of water vapour on the radiation budget. For example, the CAVIAR continuum enhances the clear-sky TOA net irradiance by $0.1 \%$ (Table 2 ) and yet it enhances the effect of increases in water vapour amount by $15 \%$ (Table 3). Similarly, the CAVIAR continuum enhances all-sky atmospheric absorption by $3 \%$, and yet it enhances the effect of increases in water vapour by $15 \%$. This is because, under both present-day and future conditions, many of the near-infrared bands of water vapour are already completely absorbing - the effect of changes in water vapour amount is mainly felt in the windows and band-edge regions, where the continuum absorption is most effective.

\subsection{Strength of the water vapour feedback}

The impact of the continuum representation on the water vapour feedback can be assessed by considering its impact on the TOA net irradiances. Table 3 shows that the impact is approximately a factor of 2 greater for all skies than for clear skies, because in a cloudy atmosphere, more upward irradiance is available to be absorbed by the increased water vapour. To place the results in context, Colman $(2001,2003)$, for example, presents water vapour feedback values from a number of models and for the short- and long-wave components. The total feedback corresponds to around $1.7 \mathrm{~W} \mathrm{~m}^{-2} \mathrm{~K}^{-1}$ (where $\mathrm{K}^{-1}$ refers to the surface temperature change), of which the short-wave component is about $15 \%$ or about $0.25 \mathrm{~W} \mathrm{~m}^{-2} \mathrm{~K}^{-1}$. Although the short-wave component of the water vapour feedback appears relatively small, it is still (as pointed out by W. Ingram, 2009; personal communication) of roughly the same size as the snow/ice albedo feedback (Colman, 2003) which has attracted much more attention in the literature.

The values in Table 3, as they are for a global-mean surface warming of $4.4 \mathrm{~K}$, are consistent with the above values, ranging from $0.24 \mathrm{~W} \mathrm{~m}^{-2} \mathrm{~K}^{-1}$ for the no-continuum case to $0.26 \mathrm{~W} \mathrm{~m}^{-2} \mathrm{~K}^{-1}$ using CAVIAR. CKD enhances the short-wave water vapour feedback by about $4 \%$, while CAVIAR enhances it by $9 \%$. Hence, the CAVIAR near-infrared continuum enhances the total (short-wave and long-wave) water vapour feedback by about $1.4 \%$, a little over double the value due to CKD.

\subsection{Impact on future 'global dimming'}

Garratt et al. (1999) drew attention to the impact of projected future changes in water vapour on downward short-wave irradiances at the surface. More recently Haywood et al. (2011) placed water-vapour induced changes in the context of clear-sky global dimming and brightening, due to past and possible future changes in anthropogenic aerosol loading. For a future scenario which leads to large warming towards the end of this century (the so-called RCP8.5 scenario), Haywood et al. (2011) found the decrease in downward short-wave irradiances due to water vapour to dominate over the effect of projected aerosol changes. The water vapour increase is projected to lead to a global-mean decrease of about $6 \mathrm{~W} \mathrm{~m}^{-2}$ by 2090 , about six times larger than the brightening resulting from the projected general decrease in 


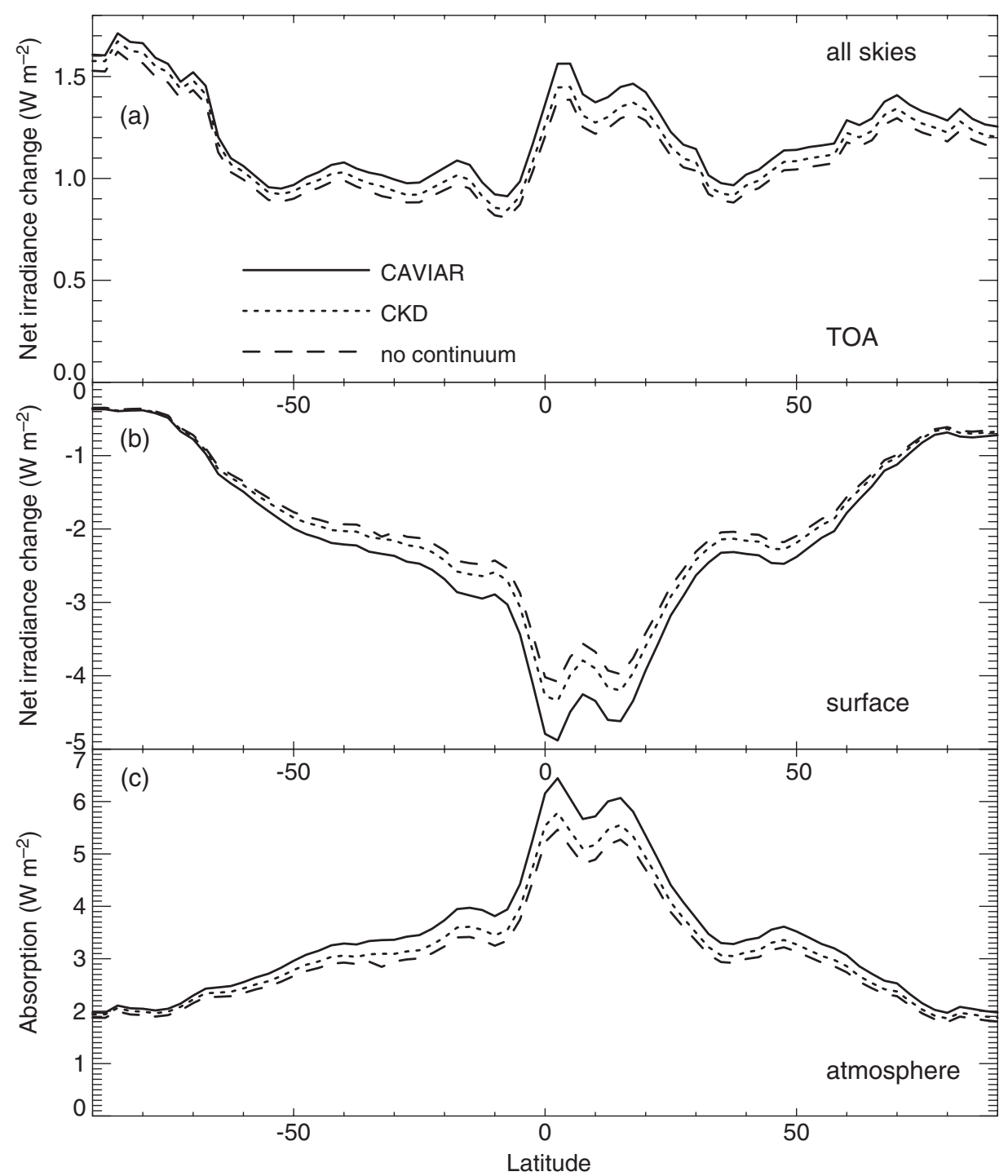

Figure 5. As Figure 4, but for the all-sky case.

aerosol loading. To place this in context, the estimated globalmean dimming to date is about $2.5 \mathrm{~W} \mathrm{~m}^{-2}$ (e.g. Haywood et al., 2011), which is dominated by increases in aerosol loading.

Table 3 (see the 'Surface Down' rows) shows that the clearsky dimming due to enhanced water vapour is about $4 \mathrm{~W} \mathrm{~m}^{-2}$ following the $4.4 \mathrm{~K}$ global-mean surface temperature change, and depends on which continuum is used. In terms of change per unit column water vapour change, this is about $0.6 \mathrm{~W} \mathrm{~m}^{-2}$ $\left(\mathrm{kg} \mathrm{m}^{-2}\right)^{-1}$. This is somewhat less than that found by Haywood et al. (2011) $\left(0.8 \mathrm{~W} \mathrm{~m}^{-2}\left(\mathrm{~kg} \mathrm{~m}^{-2}\right)^{-1}\right)$ but within the range $\left(0.6-0.73 \mathrm{~W} \mathrm{~m}^{-2}\left(\mathrm{~kg} \mathrm{~m}^{-2}\right)^{-1}\right)$ reported by Garratt et al. (1999).

The contribution of the continuum to this dimming is quite marked. In clear skies, CKD causes the dimming to be about 7\% greater than the no-continuum case, with CAVIAR causing 10\% more dimming than $\mathrm{CKD}$, indicating a total continuum effect of around $18 \%$. This emphasizes the importance of including an updated continuum in any assessments of future dimming. The all-sky absolute values (assuming no changes in cloudiness) are about $25 \%$ smaller, but the percentage contribution of the continuum (14\% for CAVIAR) is about the same as under clear skies.

Figure 6(a) shows the geographical distribution of the change in the clear-sky annual-mean downward short-wave irradiance at the surface, for the $33 \%$ increase in water vapour column, using CAVIAR. As expected, the peak decrease (exceeding $8 \mathrm{~W} \mathrm{~m}^{-2}$ in some locations) is located in the Tropics. The geographical distribution is due to variations in both the change in water column and in the available solar irradiance. Since the change shown in this Figure is a result of increases in both line and continuum absorption, Figure 6(b) shows the contribution of the continuum only to the reduction. The strong peak in the Tropics is due mostly to the self-continuum, for which the absorption scales with the square of the vapour pressure, but the increase remains significant in the extratropics because of the role of the foreign-continuum.

\subsection{Impact on future precipitation change}

Recent articles have drawn attention to the radiative control of future precipitation changes. A simple global-mean conceptual view indicates that increasing radiative divergence due to the warming atmosphere must be approximately balanced by the increased latent heating due to increased precipitation (e.g. Allen and Ingram, 2002; Stephens and Ellis, 2008).

Takahashi (2009) has drawn particular attention to the role of atmospheric short-wave absorption in this balance (a term that was neglected in some earlier studies), in his analysis of the response of several climate models to idealized $\mathrm{CO}_{2}$ forcing. The basic framework is that, if changes in sensible heat can be neglected, then atmospheric energy balance dictates that

$$
\Delta L H=\Delta L W_{\mathrm{div}}-\Delta S W_{\mathrm{abs}}
$$

where $\Delta L H$ is the change in latent heating (and is hence directly related to precipitation change), $\Delta L W_{\text {div }}$ is the change in net atmospheric long-wave divergence following climate change (as a result of changes in temperature and atmospheric composition) 

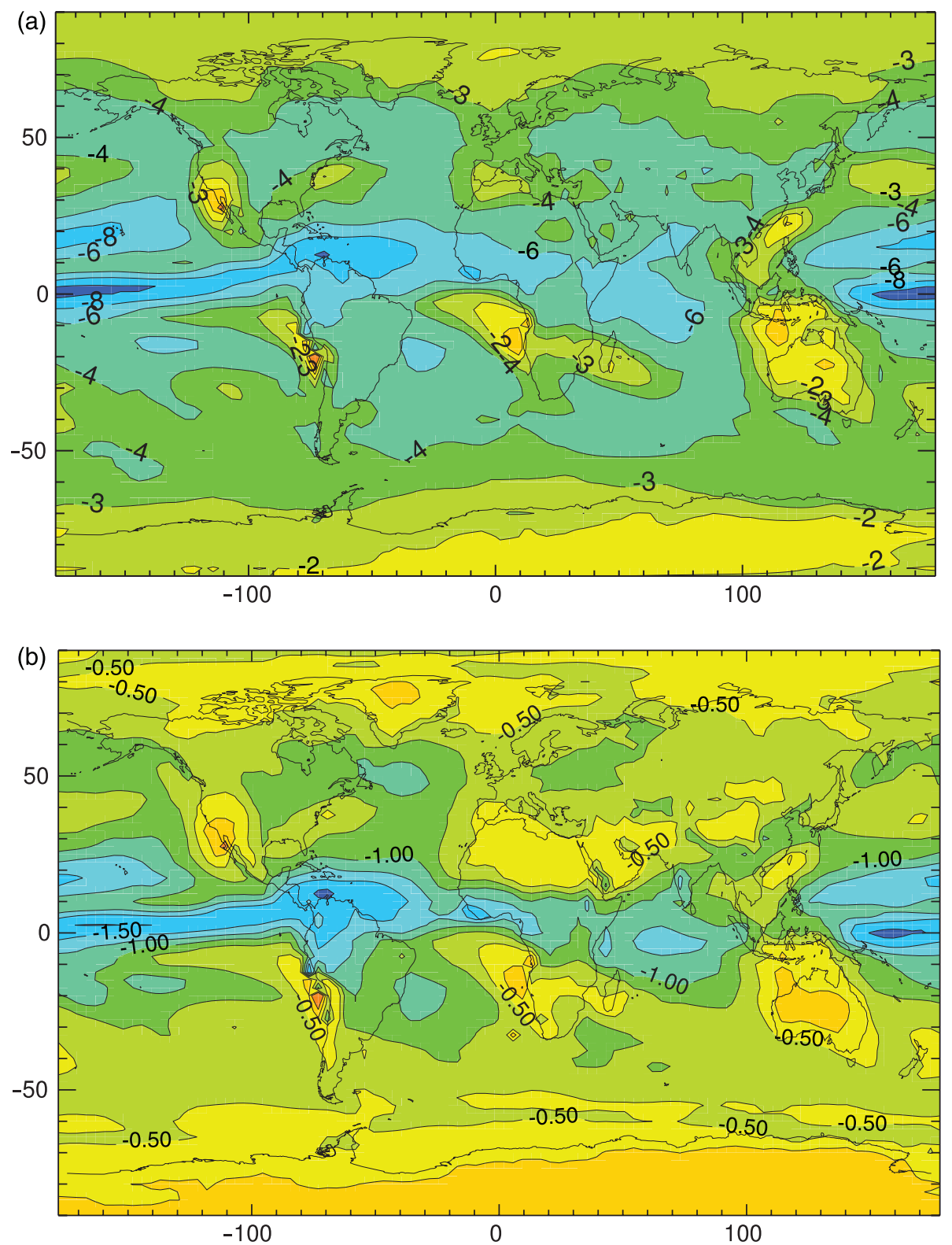

Figure 6. (a) Annual-mean change (in $\mathrm{W} \mathrm{m}^{-2}$ ) of downward solar irradiance at the surface for clear skies using the water vapour change (33\% increase in global-mean total water column) from a climate model about 65 years after the instantaneous doubling of $\mathrm{CO}_{2}$ (see section 2 for details) using the CAVIAR continuum. The contour interval is $1 \mathrm{~W} \mathrm{~m}^{-2}$ for changes less than $4 \mathrm{~W} \mathrm{~m}^{-2}$ in magnitude and $2 \mathrm{~W} \mathrm{~m}^{-2}$ above this. (b) Contribution of the continuum itself to the change shown in the top frame, for the CAVIAR continuum case. The contour interval is $0.5 \mathrm{~W} \mathrm{~m}^{-2}$.

and $\Delta S W_{\text {abs }}$ is the change in atmospheric short-wave absorption. Here, quantities are mostly quoted in $\mathrm{W} \mathrm{m}^{-2} \mathrm{~K}^{-1}$, (where $\mathrm{K}^{-1}$ refers to the surface temperature change). Climate model simulations indicate that $\Delta L W_{\text {div }}$ is around $3 \mathrm{~W} \mathrm{~m}^{-2} \mathrm{~K}^{-1}$, a value that will be used here - thus if $\Delta S W_{\text {abs }}$ is ignored, the global precipitation will change at about $3.8 \% \mathrm{~K}^{-1}$ (as a $1 \%$ change in precipitation is equivalent to about $0.8 \mathrm{~W} \mathrm{~m}^{-2}$ ); as noted in the earlier studies, this value is significantly smaller than the expected rate of increase in column water vapour of about $7 \% \mathrm{~K}^{-1}$.

Takahashi (2009) has shown that across a range of climate models, $\Delta S W_{\text {abs }}$ was surprisingly variable (ranging from about 0.3 to $1.1 \mathrm{~W} \mathrm{~m}^{-2} \mathrm{~K}^{-1}$ ) and that this difference was apparently predominantly due to different clear-sky responses amongst the models. Use of these values of $\Delta S W_{\text {abs }}$ in Eq. (4) indicate that global precipitation change varies from 2.4 to $3.4 \% \mathrm{~K}^{-1}$, showing a potentially non-trivial role for $\Delta S W_{\text {abs }}$ in modifying changes in precipitation, compared to the case where $\Delta S W_{\text {abs }}$ is ignored.

This same framework can be used to derive a first-order estimate for the impact of the visible and near-infrared continuum absorption on changes in precipitation. The all-sky changes in atmospheric absorption shown in Table 3 are equivalent to $\Delta S W_{\text {abs }}$ values of $0.79 \mathrm{~W} \mathrm{~m}^{-2} \mathrm{~K}^{-1}$ in the no-continuum case. Hence this 'offsets' $26 \%$ of $\Delta L W_{\text {div }}$, and the required precipitation change is $26 \%$ smaller. This offset increases to $27 \%$ using CKD, and to $29 \%$ using CAVIAR (for which $\Delta S W_{\mathrm{abs}}=$ $\left.0.88 \mathrm{~W} \mathrm{~m}^{-2} \mathrm{~K}^{-1}\right)$. These values are towards the upper end of the range diagnosed by Takahashi (2009). Since $\Delta S W_{\mathrm{abs}}$ is smaller than the $\Delta L W_{\text {div }}$ term, the impact on precipitation will be smaller - using Eq. (4), $\triangle L H$ is $2.21,2.19$ and $2.12 \mathrm{~W} \mathrm{~m}^{-2} \mathrm{~K}^{-1}$ for the no-continuum, CKD and CAVIAR cases respectively. This indicates that global-mean precipitation change is decreased, relative to the no-continuum case, by $1 \%$ for the CKD case and by $4 \%$ for the CAVIAR case.

Collins et al. (2006a) support the contention that enhanced short-wave atmospheric absorption acts to reduce precipitation, in climate models at least. They performed climate model simulations in which it was found that precipitation decreased by $2 \%$ when using a radiation code that enhanced the global- and annualmean all-sky short-wave absorption by water vapour by $3.4 \mathrm{~W}$ $\mathrm{m}^{-2}$. This sensitivity is somewhat different to that indicated above, as the experimental design was different to that utilized here (the change in short-wave absorption is part of both the forcing and the feedback in their model, rather than just part of the feedback, as assumed here); hence the results are not directly comparable. 


\section{Conclusions}

This study has examined the role of the water vapour continuum at solar wavelengths for both the present-day radiation budget, and in a possible future warmer and moister climate. The work has focused on improvements in our understanding resulting from recent laboratory observations of the strength of continuum absorption in the windows between the major near-infrared water vapour absorption bands, but it has also quantified the impact of the continuum that is used in many climate models.

For clear skies the global-mean atmospheric absorption is enhanced by $1.5 \mathrm{~W} \mathrm{~m}^{-2}$ (about $2 \%$ ) using the CKD continuum and $2.8 \mathrm{~W} \mathrm{~m}^{-2}$ (about $3.5 \%$ ) using the CAVIAR continuum, relative to a hypothetical no-continuum case; allsky enhancements are about $80 \%$ of the clear-sky values. The continuum plays a more important relative role in determining the changes in the radiation budget between the present-day and a possible future climate. The change in global-mean clear-sky absorption is increased by $8 \%$ using CKD and almost $20 \%$ using CAVIAR, with the all-sky changes about half of these values. We estimate the potential influence of these continuum models on the solar component of the water vapour feedback, on socalled 'global dimming' of surface solar irradiances and on the precipitation change in a warmer world. A fuller assessment would require climate model simulations, which would permit additional physical interactions within the climate system. The solar component of the water vapour feedback is enhanced by about 4 and $9 \%$ using CKD and CAVIAR respectively, relative to the no-continuum case. The clear-sky global dimming (i.e. the reduction in downward short-wave irradiance at the surface) is enhanced by 7 and $18 \%$. Using a simple conceptual model, we estimate that the global-mean precipitation response to a warming is decreased 1 and 4\% using CKD and CAVIAR respectively; the effect of atmospheric short-wave absorption offsets the change in long-wave divergence (which is the primary driver of global-mean precipitation changes), following a climate change, by $26 \%$ in the no-continuum case and $29 \%$ for the CAVIAR continuum.

There are numerous uncertainties in the present work resulting from incomplete understanding of the strength of water vapour continuum absorption in the near-infrared windows and the need to extrapolate the laboratory measurements to atmospheric temperatures. As noted in the introduction, measurements of near-infrared continuum in the laboratory are limited by currently available techniques. In particular, for confident analyses of continuum strength, measurements have to be made at elevated vapour pressures, which necessitate the use of high temperatures (most of the measurements reported by Ptashnik et al. (2011a) are between 350 and $472 \mathrm{~K}$ ). Room-temperature measurements are reported, but the stability of the spectrometer baseline becomes a more important issue here and uncertainties are magnified, although more recent measurements over longer laboratory paths (Ptashnik et al., 2013) have increased confidence in the near-room-temperature continuum strengths in the 2.1 and $3.8 \mu \mathrm{m}$ windows.

Although we have confidence that the continuum is significantly stronger than given by CKD in these windows, especially at elevated temperatures, the primary uncertainty in the 2.1 and $3.8 \mu \mathrm{m}$ windows is in the extrapolation of these values to atmospheric temperatures, which has to be done in the absence of a robust physical understanding of the causes of the continuum. The absorption is plausibly due to water dimers, or other water complexes, and is stronger than can be explained by existing far-wing line theories (see Ptashnik et al. (2011b) or Shine et al. (2012) for more discussion). The continuum strength in the CKD model generally lies at the lower end of the uncertainty range in the laboratory measurements, and so the results using CKD could be regarded as a lower limit to the impact of the continuum.

As noted in the introduction, it is in the shorter-wavelength near-infrared windows where uncertainty is greatest - it is also in these shorter-wavelength regions where more solar radiation is available to be absorbed. Laboratory observations in the $1.6 \mu \mathrm{m}$ windows are scarce and those that are available are in considerable disagreement (Bicknell et al., 2006; Mondelain et al., 2013; Ptashnik et al., 2013). Ptashnik et al. (2013) indicate that at near-room-temperatures the self-continuum in the $1.6 \mu \mathrm{m}$ window may be almost as strong as in the $2.1 \mu \mathrm{m}$ window; if their analysis is broadly correct it would enhance the role of the continuum significantly above that reported here. The situation in the $1.25 \mu \mathrm{m}$ window is even more uncertain. There is a clear need for further measurements to resolve these issues.

\section{Acknowledgements}

We acknowledge the modelling groups for making their model output available for analysis, the Program for Climate Model Diagnosis and Intercomparison for collecting and archiving these data, and the WCRP's Working Group on Coupled Modelling for organizing the model data analysis activity. The WCRP CMIP3 multi-model dataset is supported by the Office of Science, US Department of Energy. GR and IVP were funded by the NERC/ EPSRC CAVIAR consortium. KPS thanks Richard Allan for discussions. We thank the reviewers for their many helpful comments.

\section{References}

Allen MR, Ingram WJ. 2002. Constraints on future changes in climate and the hydrologic cycle. Nature 419: 224-232, doi: 10.1038/nature01092.

Baranov YI. 2011. The continuum absorption of $\mathrm{H}_{2} \mathrm{O}-\mathrm{N}_{2}$ mixtures in the $2000-3250 \mathrm{~cm}^{-1}$ spectral region at temperatures from 326-363 K. J. Quant. Spectrosc. Radiat. Transfer 112: 2281-2286, doi: 10.1016/j.jqsrt.2011.06.005.

Baranov YI, Lafferty WJ. 2011. The water vapor continuum and selective absorption in the 3 to $5 \mu \mathrm{m}$ spectral region at temperatures from 311 to 363 K. J. Quant. Spectrosc. Radiat. Transfer 112: 1304-1313, doi: 10.1016/j.jqsrt.2011.01.024.

Baranov YI, Lafferty WJ. 2012. The water vapour self- and water-nitrogen continuum absorption in the 1000 and $2500 \mathrm{~cm}^{-1}$ atmospheric windows. Philos. Trans. R. Soc. A 370: 2578-2589, doi: 10.1098/rsta.2011.0234.

Bicknell WE, Cecca SD, Griffin MK, Swartz SD, Flusberg A. 2006. Search for low-absorption regions in the 1.6 and $2.1 \mu \mathrm{m}$ atmospheric windows. J. Dir. Energy 2: 151-161.

Burch DE, Alt RT. 1984. 'Continuum absorption by $\mathrm{H}_{2} \mathrm{O}$ in the $700-1200 \mathrm{~cm}^{-1}$ and 2400-2800 $\mathrm{cm}^{-1}$ windows', Scientific Report AFGL-TR-84-0128. Air Force Geophysics Laboratory: Hanscom Air Force Base, MA.

Collins WD, Lee-Taylor JM, Edwards DP, Francis GL. 2006a. Effects of increased near-infrared absorption by water vapor on the climate system. J. Geophys. Res. 111: D18109, doi: 10.1029/2005JD006796.

Collins WD, Ramaswamy V, Schwarzkopf MD, Sun Y, Portmann RW, Fu Q, Casanova SEB, Dufresne JL, Fillmore DW, Forster PMD, Galin VY, Gohar LK, Ingram WJ, Kratz DP, Lefebvre MP, Li J, Marquet P, Oinas V, Tsushima Y, Uchiyama T, Zhong WY. 2006b. Radiative forcing by well-mixed greenhouse gases: Estimates from climate models in the Intergovernmental Panel on Climate Change (IPCC) Fourth Assessment Report (AR4). J. Geophys. Res. 111: D14317, doi: 10.1029/2005JD006713.

Colman RA. 2001. On the vertical extent of atmospheric feedbacks. Clim. Dyn 17: 391-405, doi: 10.1007/s003820000111.

Colman R. 2003. A comparison of climate feedbacks in general circulation models. Clim. Dyn. 20: 865-873, doi: 10.1007/s00382-003-0310-z.

Edwards JM, Slingo A. 1996. Studies with a flexible new radiation code. I: Choosing a configuration for a large-scale model. Q. J. R. Meteorol. Soc. 122: 689-719, doi: 10.1002/qj.49712253107.

Garratt JR, O’Brien DM, Dix MR, Murphy JM, Stephens GL, Wild M. 1999. Surface radiation fluxes in transient climate simulations. Global Planet. Change 20: 33-55, doi: 10.1016/s0921-8181(98)00059-9.

Haywood JM, Bellouin N, Jones A, Boucher O, Wild M, Shine KP. 2011. The roles of aerosol, water vapor and cloud in future global dimming/ brightening. J. Geophys. Res. 116: D20203, doi: 10.1029/2011JD016000.

Kato S, Loeb NG, Rose FG, Doelling DR, Rutan DA, Caldwell TE, Yu L, Weller RA. 2013. Surface irradiances consistent with CERES-derived topof-atmosphere shortwave and longwave irradiances. J. Clim. 26: 2719-2740, doi: 10.1175/JCLI-D-12-00436.1.

Kiehl JT, Trenberth KE. 1997. Earth's annual global mean energy budget. Bull. Am. Meteorol. Soc. 78: 197-208, doi: 10.1175/1520-0477(1997) 078<0197:EAGMEB > 2.0.CO;2.

Kim D, Ramanathan V. 2012. Improved estimates and understanding of global albedo and atmospheric solar absorption. Geophys. Res. Lett. 39: L24704, doi: 10.1029/2012GL053757. 
Li D, Shine KP. 1995. 'A 4-dimensional ozone climatology for UGAMP models', UGAMP Internal report 35. Department of Meteorology, University of Reading: Reading, UK.

Mitsel' AA, Ptashnik IV, Firsov KM, Fomin BAB. 1995. Efficient technique for line-by-line calculating the transmittance of the absorbing atmosphere. Atmos. Oceanic Opt. 8: 1547-1551.

Mlawer EJ, Payne VH, Moncet JL, Delamere JS, Alvarado MJ, Tobin DC. 2012. Development and recent evaluation of the MT_CKD model of continuum absorption. Philos. Trans. R. Soc. A 370: 2520-2556, doi: 10.1098/rsta. 2011.0295.

Mondelain D, Aradj A, Kassi S, Campargue A. 2013. The water vapour selfcontinuum by CRDS at room temperature in the $1.6 \mu \mathrm{m}$ transparency window. J. Quant. Spectrosc. Radiat. Transfer 130: 381-391, doi: 10.1016/j.jqsrt. 2013.07.006.

Paynter DJ, Ramaswamy V. 2011. An assessment of recent water vapor continuum measurements upon longwave and shortwave radiative transfer. J. Geophys. Res. 116: D20302, doi: 10.1029/2010JD015505.

Paynter D, Ramaswamy V. 2012. Variations in water vapor continuum radiative transfer with atmospheric conditions. J. Geophys. Res. 117: D16310, doi: 10.1029/2012JD017504.

Paynter DJ, Ptashnik IV, Shine KP, Smith KM, McPheat R, Williams RG. 2009. Laboratory measurements of the water vapor continuum in the 1200-8000 $\mathrm{cm}^{-1}$ region between $293 \mathrm{~K}$ and 351 K. J. Geophys. Res. 114: D21301, doi: 10.1029/2008JD011355.

Ptashnik IV, Shine KP. 2003. Calculation of solar radiative fluxes in the atmosphere: The effect of updates in spectroscopic data. Atmos. Oceanic Opt. 16: 251-255.

Ptashnik IV, Smith KM, Shine KP, Newnham DA. 2004. Laboratory measurements of water vapour continuum absorption in spectral region 5000-5600 $\mathrm{cm}^{-1}$ : Evidence for water dimers. Q. J. R. Meteorol. Soc. 130: 2391-2408, doi: 10.1256/qj.03.178.

Ptashnik IV, McPheat RA, Shine KP, Smith KM, Williams RG. 2011a. Water vapor self-continuum absorption in near-infrared windows derived from laboratory measurements. J. Geophys. Res. 116: D16305, doi: 10.1029/ 2011JD015603.

Ptashnik IV, Shine KP, Vigasin AA. 2011b. Water vapour self-continuum and water dimers: 1. Analysis of recent work. J. Quant. Spectrosc. Radiat. Transfer 112: 1286-1303, doi: 10.1016/j.jqsrt.2011.01.012.

Ptashnik IV, McPheat RA, Shine KP, Smith KM, Williams RG. 2012. Water vapour foreign-continuum absorption in near-infrared windows from laboratory measurements. Philos. Trans. R. Soc. A 370: 2557-2577, doi: 10.1098/ rsta.2011.0218.

Ptashnik IV, Petrova TM, Ponomarev YN, Shine KP, Solodov AA, Solodov AM. 2013. Near-infrared water vapour self-continuum at close to room temperature. J. Quant. Spectrosc. Radiat. Transfer 120: 23-35, doi: 10.1016/j.jqsrt. 2013.02.016.

Rossow WB, Schiffer RA. 1999. Advances in understanding clouds from ISCCP. Bull. Am. Meteorol. Soc. 80: 2261-2287, doi: 10.1175/1520-0477(1999)080 $<2261$ :AIUCFI > 2.0.CO;2.

Rothman LS, Gordon IE, Babikov Y, Barbe A, Benner DC, Bernath PF, Birk M, Bizzocchi L, Boudon V, Brown LR, Campargue A, Chance K, Cohen EA, Coudert LH, Devi VM, Drouin BJ, Fayt A, Flaud J-M, Gamache RR, Harrison JJ, Hartmann J-M, Hill C, Hodges JT, Jacquemart D, Jolly A,
Lamouroux J, Le Roy RJ, Li G, Long DA, Lyulin OM, Mackie CJ, Massie ST, Mikhailenko S, Müller HSP, Naumenko OV, Nikitin AV, Orphal J, Perevalov V, Perrin A, Polovtseva ER, Richard C, Smith MAH, Starikova E, Sung K, Tashkun S, Tennyson J, Toon GC, Tyuterev VG, Wagner G. 2013. The HITRAN2012 molecular spectroscopic database. J. Quant. Spectrosc. Radiat. Transfer 130: 4-50, doi: 10.1016/j.jqsrt.2013.07.002.

Shine KP, Ptashnik IV, Rädel G. 2012. The water vapour continuum: Brief history and recent developments. Surv. Geophys. 33: 535-555, doi: 10.1007/ s10712-011-9170-y.

Stephens GL, Ellis TD. 2008. Controls of global-mean precipitation increases in global warming GCM experiments. J. Clim. 21: 6141-6155, doi: 10.1175/2008jcli2144.1.

Stephens GL, Li JL, Wild M, Clayson CA, Loeb N, Kato S, L'Ecuyer T, Stackhouse PW, Lebsock M, Andrews T. 2012. An update on Earth's energy balance in light of the latest global observations. Nat. Geosci. 5: 691-696, doi: 10.1038/ngeo1580.

Sudradjat A, Ferraro RR, Fiorino M. 2005. A comparison of total precipitable water between reanalyses and NVAP. J. Clim. 18: 1790-1807, doi: $10.1175 /$ jcli3379.1.

Takahashi K. 2009. The global hydrological cycle and atmospheric shortwave absorption in climate models under $\mathrm{CO}_{2}$ forcing. J. Clim. 22: 5667-5675, doi: 10.1175/2009jcli2674.1.

Tallis L, Coleman M, Gardiner T, Ptashnik IV, Shine KP. 2011. Assessment of the consistency of $\mathrm{H}_{2} \mathrm{O}$ line intensities over the near-infrared using sunpointing ground-based Fourier transform spectroscopy. J. Quant. Spectrosc. Radiat. Transfer 112: 2268-2280, doi: 10.1016/j.jqsrt.2011.06.007.

Trenberth KE, Fasullo JT. 2012. Tracking Earth's energy: From El Niño to global warming. Surv. Geophys. 33: 413-426, doi: 10.1007/s10712-0119150-2.

Uppala SM, Kållberg PW, Simmons AJ, Andrae U, Bechtold VD, Fiorino M, Gibson JK, Haseler J, Hernandez A, Kelly GA, Li X, Onogi K, Saarinen S, Sokka N, Allan RP, Andersson E, Arpe K, Balmaseda MA, Beljaars ACM, Van De Berg L, Bidlot J, Bormann N, Caires S, Chevallier F, Dethof A, Dragosavac M, Fisher M, Fuentes M, Hagemann S, Hólm E, Hoskins BJ, Isaksen L, Janssen P, Jenne R, McNally AP, Mahfouf JF, Morcrette JJ, Rayner NA, Saunders RW, Simon P, Sterl A, Trenberth KE, Untch A, Vasiljevic D, Viterbo P, Woollen J. 2005. The ERA-40 re-analysis. Q. J. R. Meteorol. Soc. 131: 2961-3012, doi: 10.1256/qj.04.176.

Vonder Haar TH, Bytheway JL, Forsythe JM. 2012. Weather and climate analyses using improved global water vapor observations. Geophys. Res. Lett. 39: L15802, doi: 10.1029/2012GL052094.

Wild M, Folini D, Schar C, Loeb N, Dutton EG, Konig-Langlo G. 2013. The global energy balance from a surface perspective. Clim. Dyn. 40: 3107-3134, doi: 10.1007/s00382-012-1569-8.

Zhong WY, Haigh JD, Belmiloud D, Schermaul R, Tennyson J. 2001. The impact of new water vapour spectral line parameters on the calculation of atmospheric absorption. Q. J. R. Meteorol. Soc. 127: 1615-1626, doi: 10.1002/qj.49712757508.

Zhong WY, Haigh JD, Belmiloud D, Schermaul R, Tennyson J. 2002. Note on 'The impact of new water vapour spectral line parameters on the calculation atmospheric absorption' by Wenyi Zhong et al. (July A, 2001, 127, 1615-1626). Q. J. R. Meteorol. Soc. 128: 1387-1388, doi: 10.1256/ 003590002320373346 . 